\title{
AVALIAÇÃO DA QUALIDADE MICROBIOLÓGICA DE ÁGUAS E SUPERFÍCIES DE BEBEDOUROS DE PARQUES DE CURITIBA - PR
}

\section{MICROBIOLOGICAL EVALUATION OF WATER AND SURFACES OF DRINKING FOUNTAINS OF PARKS FROM CURITIBA - PR}

\author{
REIS, Francini'; DIAS, Camila R. ; ABRAHÃO, Wanda M. ${ }^{2}$ \& MURAKAMI, Fábio S. ${ }^{1,2}$
}

1. Curso de Farmácia - Universidade Positivo - CEP 81280330 - Curitiba - PR

2. Laboratório de Controle de Qualidade II - Departamento de Farmácia - Universidade Federal do Paraná (UFPR) - Av. Pref. Lothário Meissner, 632, Jardim Botânico, 80210-170, Curitiba, PR. (fsmurakami@ufpr.br)

\section{RESUMO:}

A qualidade da água é uma questão de saúde pública e a segurança dos consumidores deve ser garantida através das especificações que determinam as condições favoráveis para consumo. Este trabalho teve como principal objetivo avaliar condições higiênico-sanitárias de águas e superfícies de bebedouros presentes em dois parques na região de Curitiba-PR. Os testes aplicados para este estudo foram pesquisa de coliformes totais e termotolerantes que são importantes indicadores sanitários para prevenir a ocorrência de surtos de contaminação microbiana através da ingestão de águas e a contagem de bactérias heterotróficas e bolores e leveduras que são necessários para garantir a qualidade da água e avaliar as condições de higiene. Os resultados encontrados indicam que as águas fornecidas nestes parques apresentam condições higiênicas sanitárias adequadas para consumo. Considerando a superfície dos bebedouros observou-se que o resultado obtido no segundo dia de analise ocorreu um aumento significativo na quantidade de unidades formadoras de colônias tanto para bactérias heterotróficas como bolores e leveduras. Este fato pode justificado devido o aumento da temperatura, umidade e a higienização inadequada do local.

Palavras-chave: Controle Microbiológico, Águas, Bebedouros e Parques de CuritibaPR.

\section{ABSTRACT:}

The drinking water quality is a public health concern and the population safety should be guaranteed by the specifications that determine the conditions for consumption. The main purpose of this work was to evaluate the microbiological quality of water and surfaces of two drinking fountains from parks of Curitiba - PR. The tests carried out in this study were the presence of total coliforms and thermotolerant using two different methods (conventional and fast), in which indicates the microbial fecal contamination 
and the enumeration of heterotrophic bacteria and yeasts and molds that are needed to ensure water quality and the conditions of hygiene. The results demonstrated that the water provided in these parks have adequate sanitary hygienic conditions for consumption. Considering the surface of the drinking fountain was observed that the result obtained on the second day of analysis was increase in the enumeration of heterotrophic bacteria and yeasts and molds. This fact can be justified due to the increase of temperature, humidity and inadequate hygiene.

Key words: Microbiological Quality Control, Water, Drinking Fountains and Parks of Curitiba-Pr.

\section{INTRODUÇÃO}

Aágua constitui um elemento imprescindível à existência do ser humano e está presente em todos os seguimentos da vida. Embora seja um elemento essencial, a água também pode trazer riscos à saúde se for de má qualidade, servindo de veículo para vários agentes biológicos e químicos (CARVALHO; RECCO PIMENTEL, 2007).

A qualidade da água tornou-se uma questão de saúde pública no final do século $\mathrm{XIX}$ e início do século $X X$, devido à compreensão entre a relação água contaminada e as doenças. As doenças transmitidas pela água são caracterizadas principalmente pela ingestão de microrganismos patogênicos de origem entérica, animal ou humana, transmitidos basicamente pela rota fecal-oral (BERTAGNOLLI, et al., 2003; SILVA, ARAÚJO, 2003; LIBÂNIO; CHERNICHARRO; NASCIMENTO, HELLER, 2005; TORTORA; FUNKE; CASE, 2005).

Dados da Organização Mundial de Saúde (OMS) revelam que $80 \%$ das doenças nos países em desenvolvimento são causadas pela água contaminada. $A$ contaminação microbiana dos principais sistemas urbanos tem o potencial de causar grandes surtos de doenças transmitidas pela água, portanto garantir a qualidade de tais sistemas é uma prioridade (FERNANDEZ; SANTOS, 2007; COELHO et al., 2007; WHO, 2008).

A qualidade da água é de responsabilidade do estado e da nação, devendo o primeiro assegurar que seja feita a gestão adequada dos recursos hídricos, e o segundo de usar o recurso conscientemente. A garantia de segurança e de potabilidade da água depende do funcionamento adequado de diversas etapas no processo de abastecimento, que vão desde o tratamento até a distribuição e, caso alguma delas apresente falhas, pode desencadear um processo de contaminação (BRASIL, 2011).

Dentre os principais usos da água, o abastecimento público é o uso mais nobre devendo esta ser considerada potável, ou seja, devem atender aos parâmetros microbiológicos, físicos, químicos e radioativos definidos pela legislação vigente e não 
não oferecer riscos à saúde do consumidor (SPERLING, 1996; BRASIL, 2011).

A norma de qualidade de água para consumo humano, aprovada na Portaria 2914/2011do Ministério da Saúde, define que o controle da água consiste no "conjunto de atividades exercidas de forma contínua pelos responsáveis destinada a verificar se a água fornecida à população é potável, assegurando a manutenção desta condição." A Norma dispõe sobre os procedimentos e responsabilidades relacionadas ao controle e à vigilância da qualidade da água nos diferentes níveis de governo e gestão (BRASIL, 2011).

A utilização de testes para a determinação de indicadores de contaminação fecal em água é a maneira mais sensível e específica de estimar a qualidade da água, em relação à higiene e cuidados primários à saúde. Os métodos mais utilizados são: a quantificação de coliformes totais e fecais, seguida da enumeração de bactérias heterotróficas totais (BOMFIM et al., 2007).

A contagem de heterotróficos, também conhecida como contagem padrão em placas, é um procedimento que objetiva estimar o número de bactérias heterotróficas na água, particularmente como uma ferramenta para acompanhar as variações nas condições de processo, no caso das águas minerais, ou eficiência das diversas etapas de tratamento, no caso de águas tratadas. Permite ainda verificar as condições higiênicas em diferentes pontos da rede de distribuição. Não diferencia tipos de bactérias, sendo mais utilizadas para se obter informações sobre a qualidade de produtos, práticas de manufatura, matérias-primas utilizadas, condições de processamento, manipulação e vida de prateleira. Não é um indicador de segurança, pois não está diretamente relacionado à presença de patógenos ou toxinas, mas dependendo da situação, pode ser útil na avaliação da qualidade, porque populações altas de bactérias podem indicar deficiências na sanitização ou falha no controle de processo ou dos ingredientes (SILVA, et al 2010).

Através da Portaria vigente, fica definido que a água para consumo humano, em qualquer situação, incluindo fontes individuais, deve ser livre de Escherichia coli ou coliformes termotolerantes, sendo recomendada sua ausência em $100 \mathrm{~mL}$ e para bactérias heterotróficas no máximo 500UFC/mL. (BRASIL, 2011).

Diante deste contexto, o presente trabalho objetivou realizar o controle de qualidade microbiológico de águas e superfícies de bebedouros presentes em parques na região de Curitiba-PR.

\section{MATERIALE MÉTODOS}

\subsection{Seleção e Coleta das Amostras}

Para este estudo foram selecionados dois parques públicos ( $\mathrm{A}$ e $\mathrm{B}$ ) da cidade de Curitiba - PR que possuíam bebedouros disponíveis para a população. Foram 
coletadas duas amostras de água e duas amostras da superfície em dias com condições climáticas diferentes (18/07/2011 e 03/10/2011).

As amostras coletadas na data de 18/07/2011 foram denominadas como 1, e as coletas do dia 03/10/2011 como 2. Assim as amostras foram devidamente identificadas como $A 1, A 2, B 1$ e B2.

O procedimento de coleta da superfície dos bebedouros para posterior análise microbiológica foi realizado conforme o esquema apresentado na figura 1. As amostras foram limitadas por um gabarito de $100 \mathrm{~cm}^{2}$. Para tanto, utilizou-se um swab embebido em água peptonada $0,1 \%$ inclinado a 30 'graus, para realizar os esfregaços necessários para obter uma amostra adequada, ou seja, os esfregaços foram coletados de quatro diferentes pontos da área limitada pelo gabarito (na diagonal e vertical e em duas áreas diferentes da mesma superfície).

Para a coleta das amostras de água realizou-se a assepsia do local de saída da água com álcool $70 \%$ e posterior escoamento da água por 3 minutos. Um volume de $500 \mathrm{~mL}$ de água foi coletado em um frasco previamente esterilizado com $0,5 \mathrm{~mL}$ tiossulfato de sódio a 1,8 \%. Estas amostras foram transportadas até o laboratório de análise em isopor refrigerado.

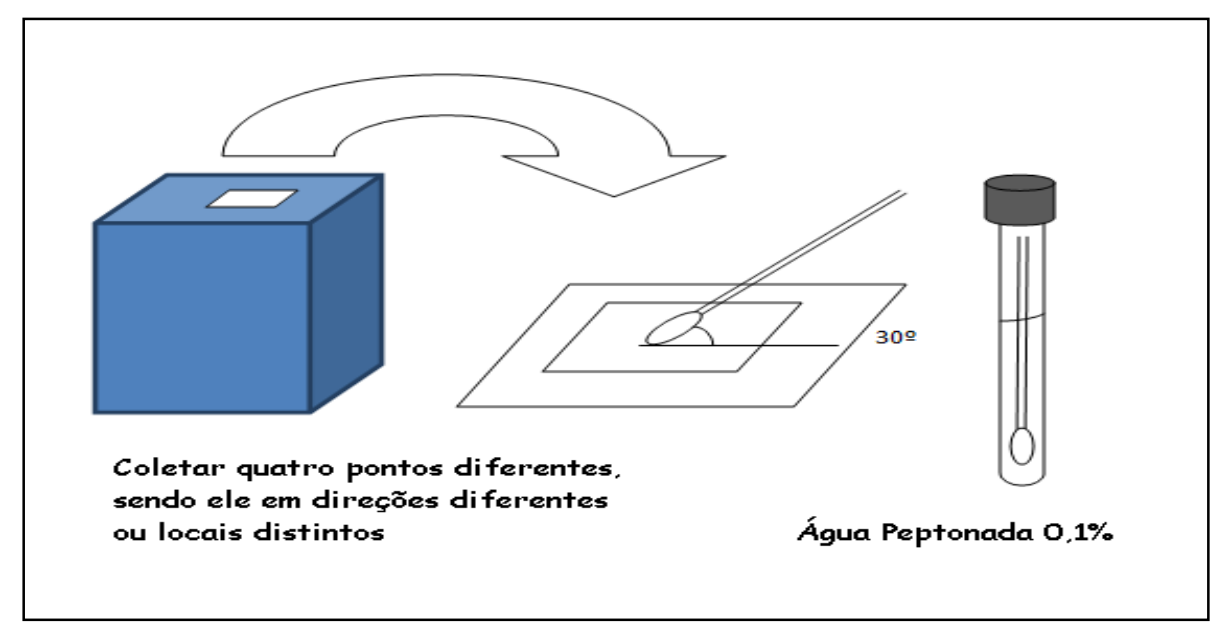

Figura 1 - Esquema ilustrativo da coleta com swab em superfície

Fonte: Os Autores

\subsection{Análises Microbiológicas da Água}

\subsubsection{Coliformes Totais e Termotolerantes (NMP - Método Convencional)}

Para a análise de coliformes totais e termotolerantes utilizou-se técnica de tubos múltiplos com três séries de tubos contendo caldo Lauril Sulfato Triptose (LST), obtendo os resultados em NMP/100mL (AMERICAN, 2005). O esquema adaptado 
adaptado pode ser evidenciado na figura 2.

A incubação foi em temperatura entre $35-37^{\circ} \mathrm{C}$ por $24-48$ horas. Após este período foi verificado se houve presença de turvação e gás que caracterizam um crescimento, ou seja, resultado positivo para o teste presuntivo.

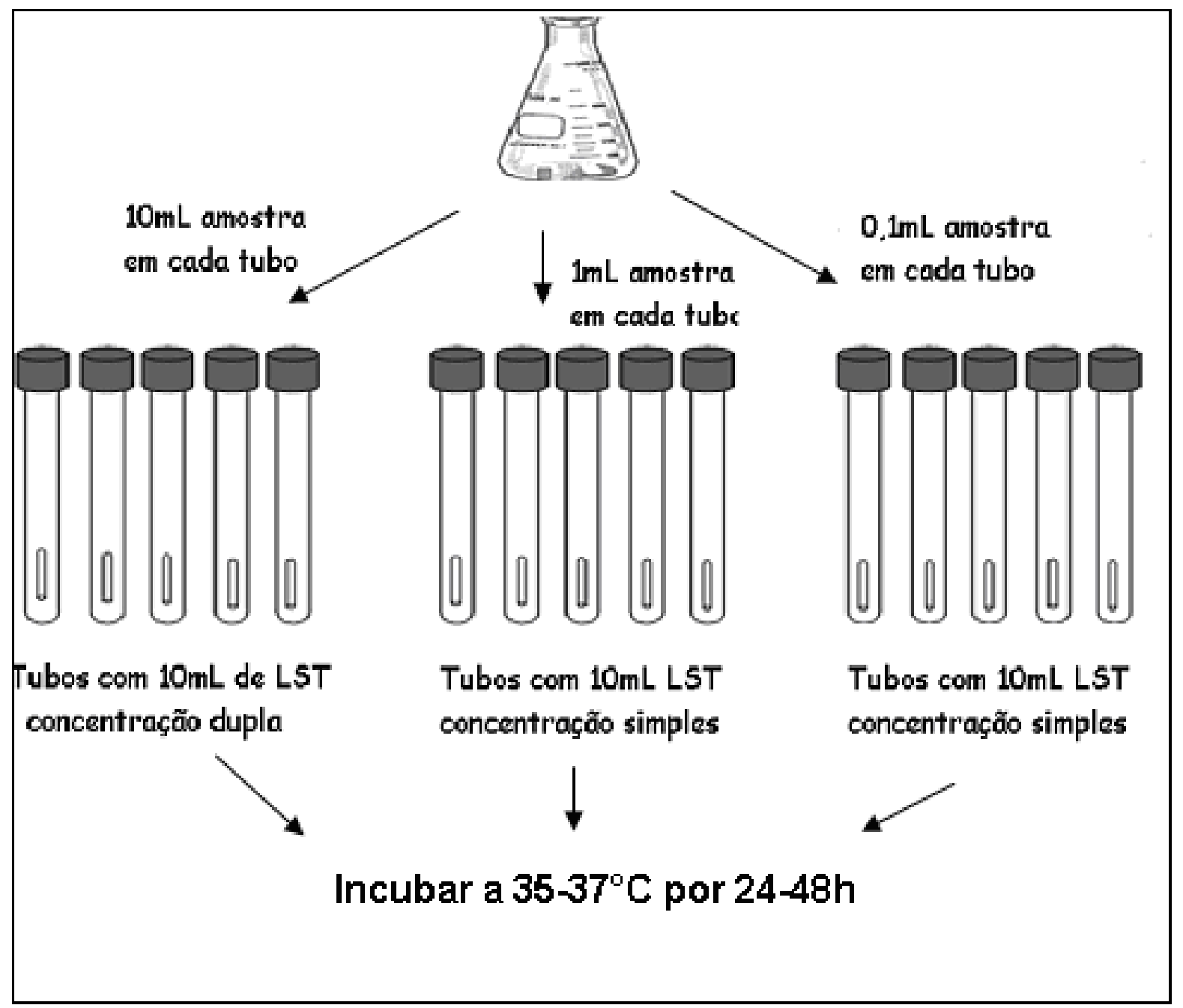

FIGURA 2 - Técnica NMP para coliformes totais e termotolerantes Fonte: Os Autores

\subsubsection{Coliformes Totais e Termotolerantes (Kit rápido - Newprov, 2010)}

Como metodologia alternativa para coliformes Totais e Termotolerantes foram analisados pelo Kit Acqua Plus $®$ II. A amostra, homogeneizada pelo menos 10 vezes, foi adicionada a tubos contendo caldo FLM (newprov®) conforme indicado na figura 3.

Os tubos com coloração verde azulada são considerados positivos para coliformes totais e os que apresentam fluorescência quando observados em ultravioleta a $365 \mathrm{~nm}$ são considerados positivos para coliformes fecais, após incubação a $35-37^{\circ} \mathrm{C}$ por 24-48horas. 


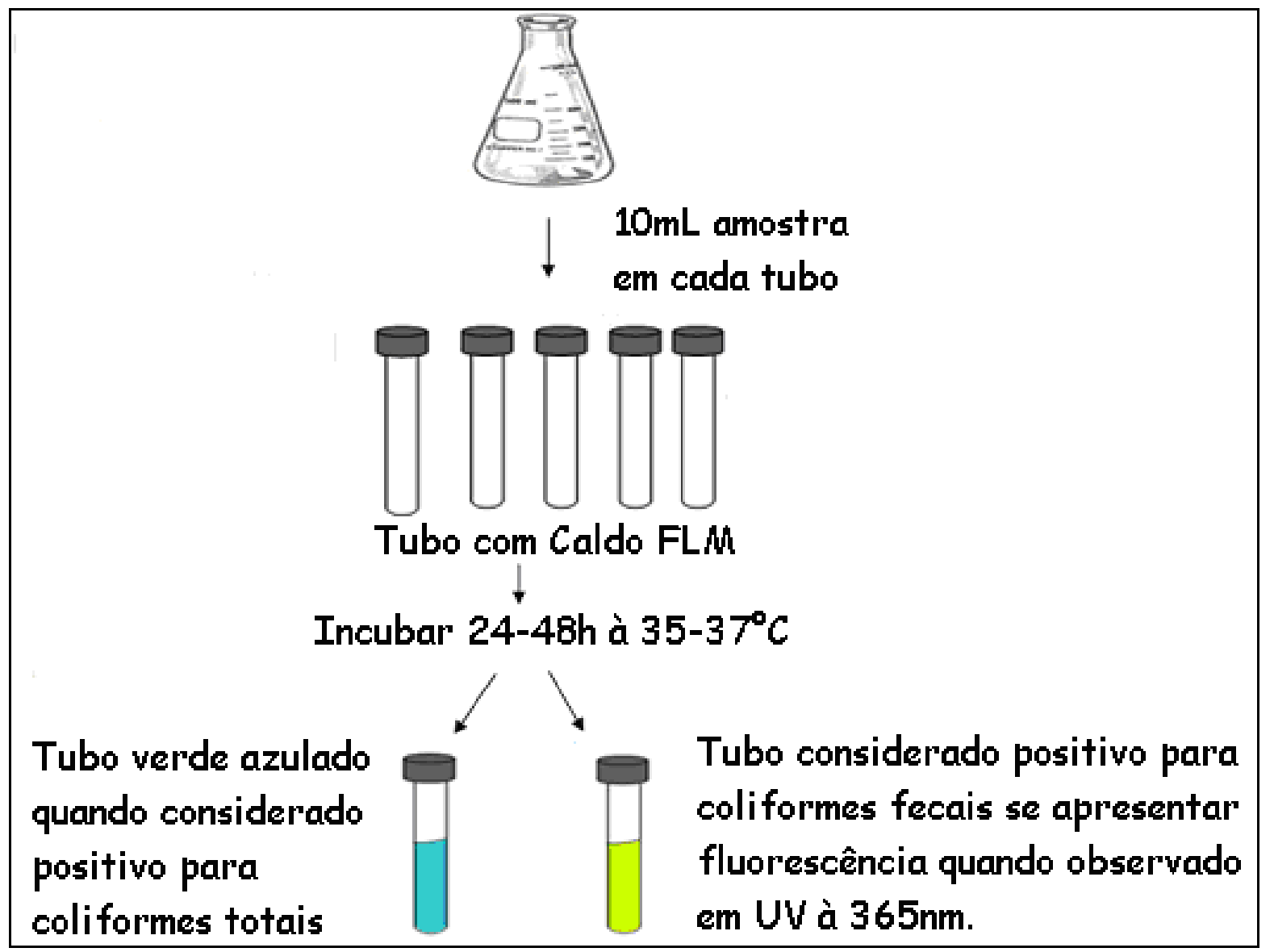

FIGURA 3 - Contagem de coliformes totais e termotolerantes utilizando KitACQUAPLUS $®$ II Fonte: Os Autores

\subsubsection{Contagem de Bactérias Heterotróficas}

As amostras de água foram diluídas em $9 \mathrm{~mL}$ de salina $0,9 \%$ até $10^{-3}$. Após utilizou-se a técnica de semeadura em profundidade, transferindo-se $1 \mathrm{~mL}$ de cada diluição para placas de petri estéreis, seguidos com $20 \mathrm{~mL}$ de ágar PCA (Plate Count Agar) e incubadas a $35-37^{\circ} \mathrm{C}$ por 24 horas. O procedimento foi realizado em duplicata (Figura 4). 


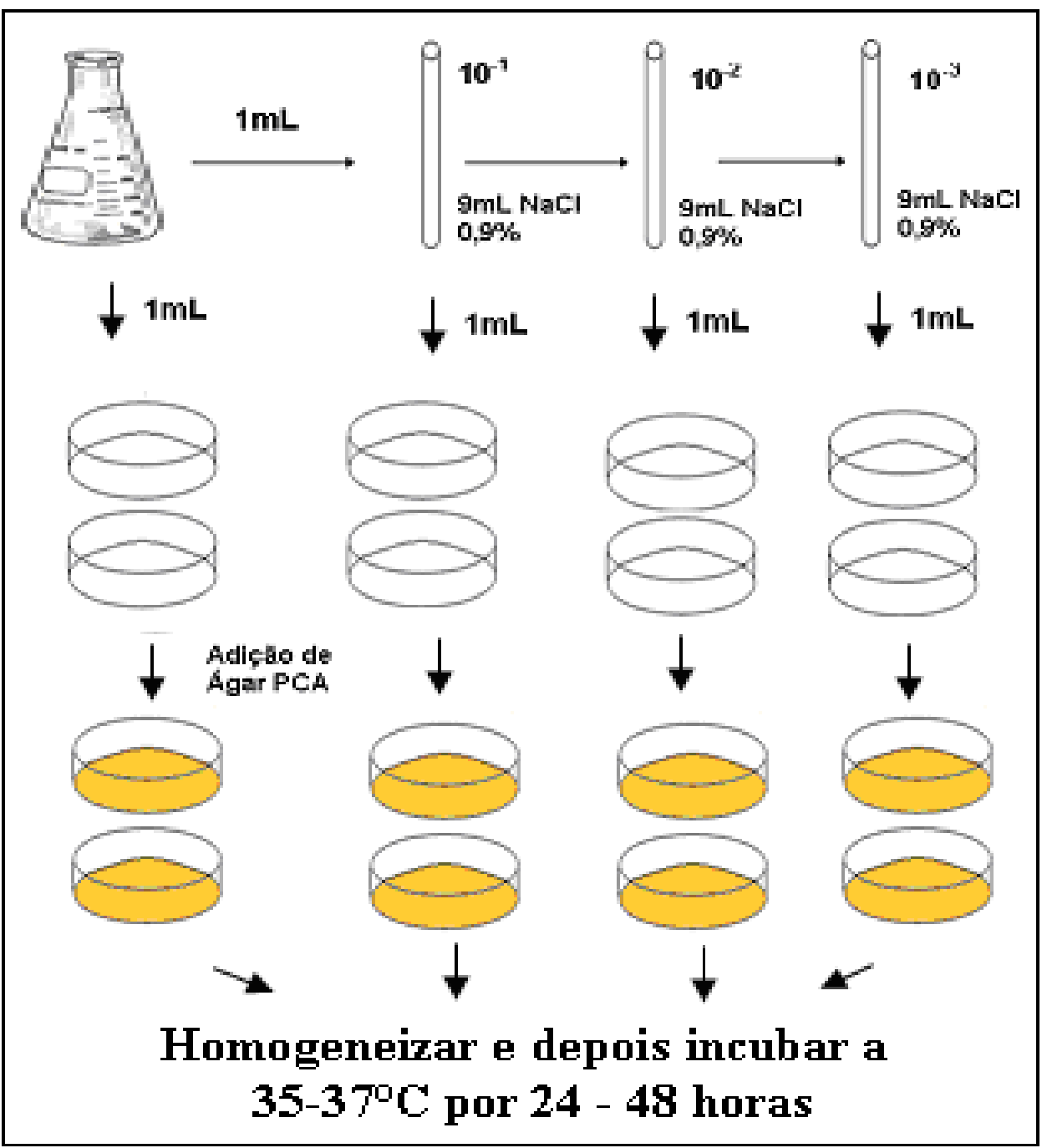

FIGURA4 - Esquema do procedimento de análise para bactérias heterotróficas em águas Fonte: Os Autores

\subsection{Análise na Superfície do Bebedouro}

\subsubsection{Coliformes Totais e Termotolerantes (NMP)}

A análise de Coliformes Totais e Termotolerantes foram efetuadas conforme descrito na figura 5. Para tanto, foram retirados $1 \mathrm{~mL}$ de amostra após o procedimento de coleta descrita no item 2.1 e colocados em tubos contendo caldo LST que foram incubados à $35-37{ }^{\circ} \mathrm{C}$ durante $24-48$ horas após inoculação da amostra e então verificou-se possível crescimento (turvação e gás) nestes tubos. 


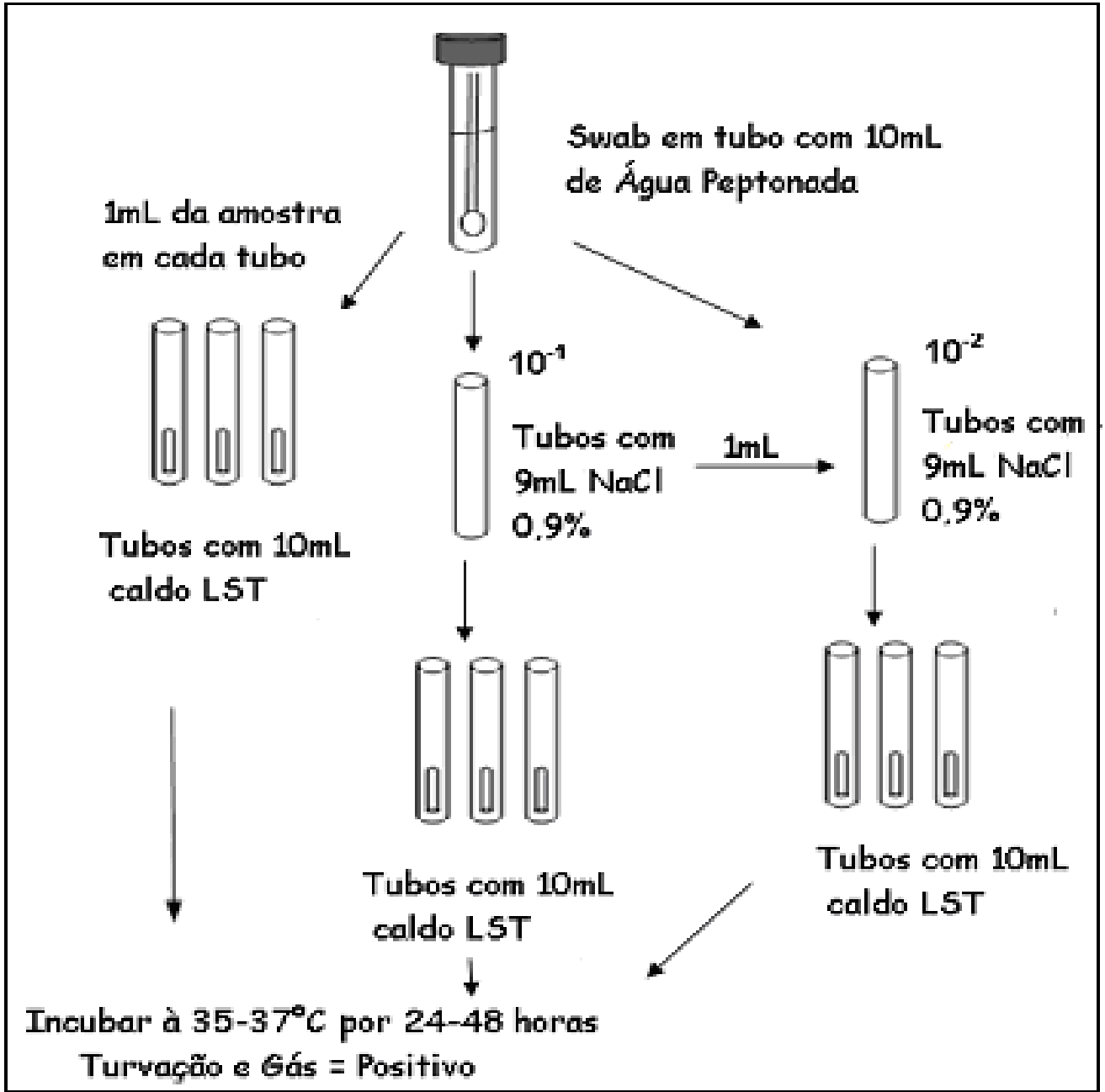

FIGURA 5 - Ilustração do processo realizado para análises presuntivas de coliformes totais e termotolerantes em superfície.

Fonte: Os Autores

\subsubsection{Contagem de Bactérias Heterotróficas}

A contagem de bactérias heterotróficas foi procedida conforme descrito na figura 6. Após o procedimento de coleta descrito no item 2.1, as amostras foram diluídas em $9 \mathrm{~mL}$ de salina $0,9 \%$ até $10^{-3}$.

A técnica foi realizada pelo método Pour plate, semeadura em profundidade. Para tanto foram retiradas alíquotas de $1 \mathrm{~mL}$ de amostra não diluída e também de cada uma das diluições e colocados em placas de petri estéreis nas quais foram vertidos $20 \mathrm{~mL}$ de ágar PCA. O cálculo foi expresso em unidades formadoras de colônias por 100 $\mathrm{cm}^{2}$. 


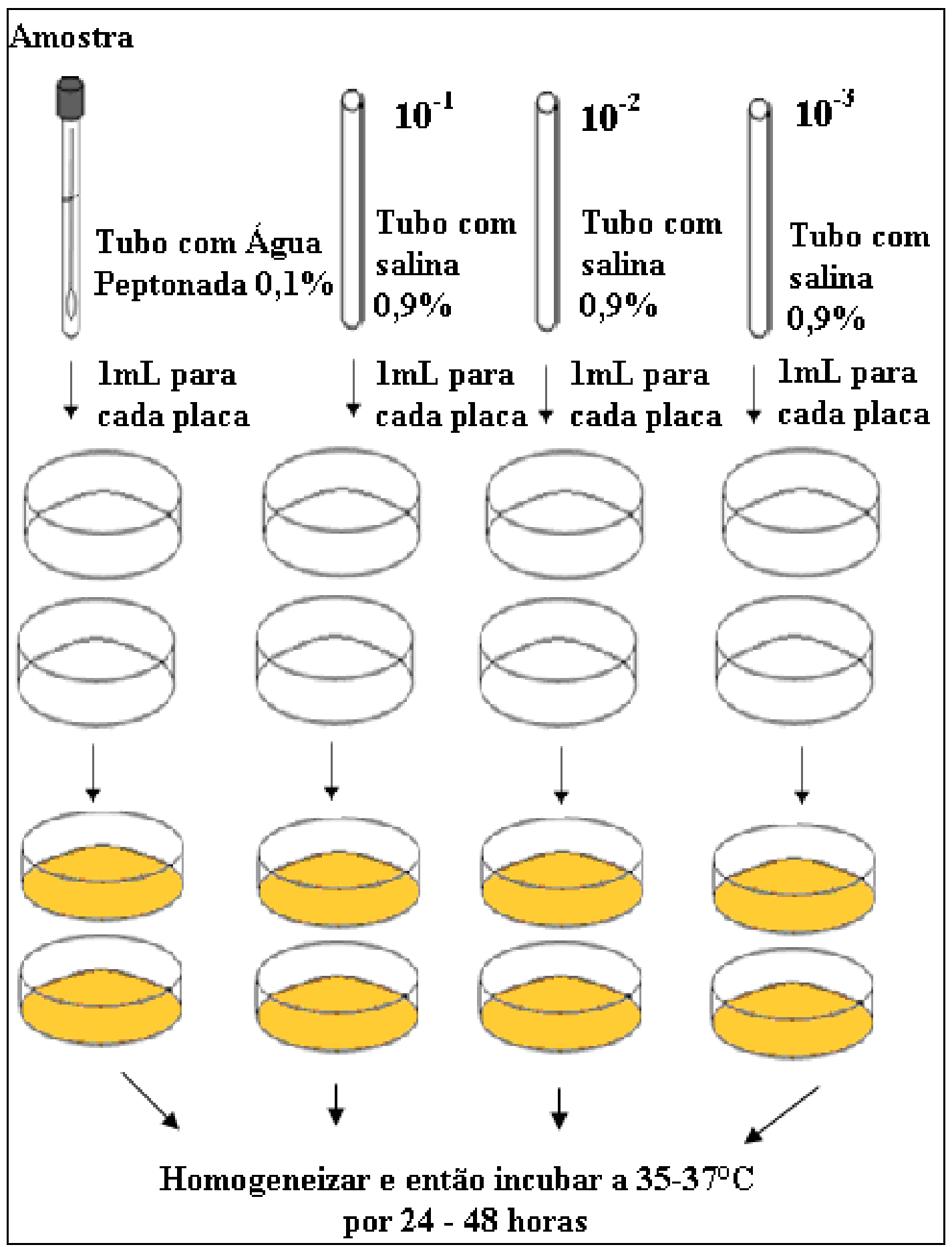

FIGURA 6 - Técnica realizada para bactérias heterotróficas em superfície Fonte: Os Autores

\subsubsection{Contagem de Bolores e Leveduras}

A contagem de bolores e leveduras foi realizada de acordo com o esquema apresentado na figura 7. Para tanto foram retirados $1 \mathrm{~mL}$ de amostra após o 
procedimento de coleta descrito no item 2.1 e colocados em placas contendo $20 \mathrm{~mL}$ de ágar Sabouraud pelo método de semeadura em superfície (Spread plate), no qual as amostras foram espalhadas sobre este ágar com auxilio de uma alça de drigalski. $\mathrm{O}$ cálculo foi expresso em unidades formadoras de colônias por $100 \mathrm{~cm}^{2}$.

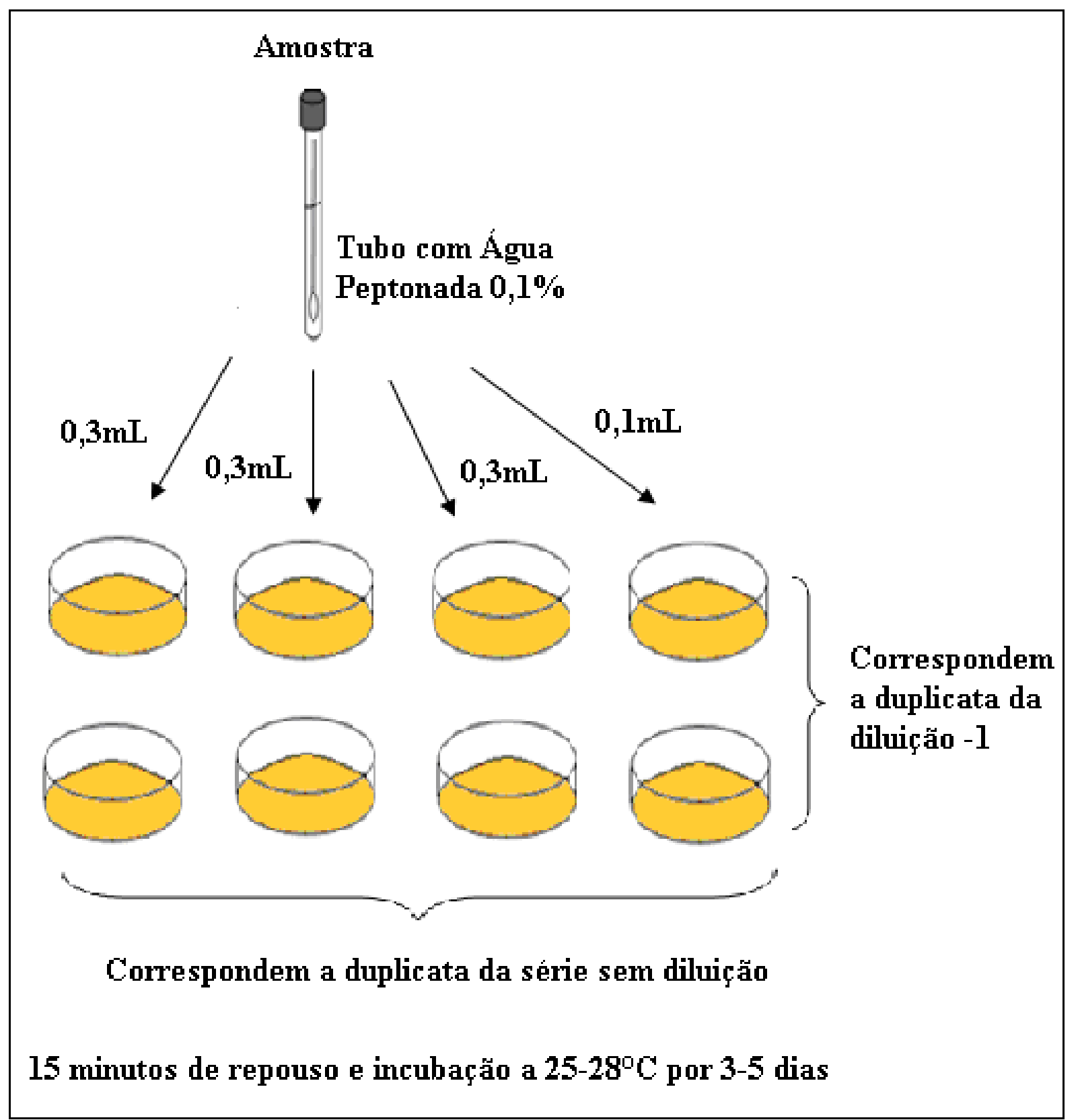

FIGURA 7 - Procedimento de contagem de bolores e leveduras em superfície Fonte: Os Autores

\section{RESULTADOS E DISCUSSÃO}

Tendo em vista como produto à água, leva-se em consideração que esta é de amplo uso e possui características propícias ao crescimento microbiano, por isso a 
necessidade de fazer o controle de qualidade a fim de verificar suas condições para consumo, evitando riscos a saúde como as doenças por agentes microbiológicos patogênicos (PINTO, KANEKO, OHARA, 2003).

A pureza da água está diretamente relaciona com a ausência de patógenos e uma carga mínima de bactérias heterotróficas estabelecidos pela United States Pharmacopeia (2000).

\subsection{Análises Microbiológicas da Água}

\subsubsection{Coliformes totais e termotolerantes}

A avaliação das condições sanitárias das amostras A1, A2, B1 e B2 foram determinadas pela análise de coliformes totais e termotolerantes, utilizando a metodologia convencional pela técnica do número mais provável e a metodologia rápida pela técnica colorimétrica enzimática Acqua plus $₫$ II

Todas as amostras apresentaram um padrão de qualidade satisfatório, uma vez que os resultados demonstraram crescimento $<1,0 \mathrm{NMP} / 100 \mathrm{~mL}$.

Durante a análise, utilizando o método convencional não houve a necessidade de realizar a etapa confirmatória devido não positividade para o teste presuntivo, ou seja, não foi observada a turvação e nem formação de gás nos tubos contendo caldo Lauril sulfato de sódio.

Os resultados corroboraram entre o método convencional e o rápido. $A$ utilização do Kit Aquaplus ${ }^{\circledR}$ II surgiu como conseqüência da necessidade de se abreviar o tempo necessário para a obtenção de resultados analíticos e melhorar a produtividade laboratorial. Esse método visa também à simplificação do trabalho e a redução de custos. Cabe ressaltar que os métodos rápidos são aprovados pelos órgãos oficiais e pode ser utilizado na rotina do controle de qualidade uma vez que resultados são considerados como definitivos.

\subsubsection{Contagem de Bactérias Heterotróficas}

Quanto à contagem de bactérias heterotróficas nas amostras, todas apresentaram um crescimento $<10 \mathrm{UFC} / \mathrm{mL}$. A partir dos resultados obtidos, abaixo do valor de referência estabelecido ( $<500 \mathrm{UFC} / \mathrm{mL}$ ), considerou-se que as amostras $\mathrm{A} 1$, A2, B1 e B2 estão próprias para o consumo humano.

Esse tipo de contagem é uma ferramenta para acompanhar a eficiência das diferentes etapas de tratamento da água e permite ainda verificar as condições em diferentes pontos da rede de distribuição e a eficiência do processo de limpeza das caixas e reservatórios de água (SILVAet al., 2010). 
Os resultados obtidos denotam que a água possui condições microbiológicas ideais para consumo, uma vez que está dentro dos parâmetros estabelecidos pela Portaria 2914 de 2011, no qual define água para consumo humano aquela livre de Escherichia coli ou coliformes termotolerantes e uma quantidade máxima de 500 UFC/mL. O resultado é expresso em NMP/100 mL de acordo com Standard Methods, tabela IV - 9221, utilizando limites de variação de resultados para cinco tubos com diluições $10 \mathrm{~mL}, 1 \mathrm{~mL}$ e 0,1 mL (AMERICAN,2005).

\subsection{Análises da Superfície}

\subsubsection{Coliformes Totais e Termotolerantes (NMP)}

Os resultados avaliados para Coliformes Totais e Termotolerantes na superfície dos bebedouros dos parques foram $<0,3 \mathrm{NMP} / \mathrm{mL}$, demonstrando condição satisfatória de higiene, considerando os valores de referência, segundo a tabela de combinação de três séries de diluição com três tubos positivos, expressos em $\mathrm{NMP} / \mathrm{mL}$.

\subsubsection{Contagem de Bactérias Heterotróficas}

Os resultados obtidos para a contagem de bactérias heterotróficas totais na superfície dos bebedouros dos parques em diferentes regiões de Curitiba - PR estão apresentados na Tabela 1.

Tabela 1 - Contagem de bactérias heterotróficas na superfície dos bebedouros de dois parques de Curitiba - Paraná

\begin{tabular}{c|c}
\hline Amostras & Resultados (UFC/100 $\left.\mathbf{c m}^{\mathbf{2}}\right)$ \\
\hline A1 & $3,3 \times 10^{2}$ \\
A2 & $1,4 \times 10^{3}$ \\
B1 & $4,3 \times 10^{2}$ \\
B2 & $1,5 \times 10^{3}$ \\
\hline
\end{tabular}

*Os valores obtidos foram determinados a partir da duplicada

Nas amostras de ambos os parques na primeira data de coleta realizada, os valores encontrados na contagem de bactérias foram baixas (A1 e B1). Porém, nas datas da segunda coleta (dia 03/10/2011) os resultados encontrados foram superiores refletindo nas condições higiênicas e sanitárias do local. 
Segundo Gomes et al. (2005), esta variação de valores pode ser atribuída a vários fatores como: as condições de sazonalidade. Na primeira data de análise (inverno) a temperatura estava mais baixa, não tendo uma condição ideal ao crescimento de bactérias (aproximadamente $15^{\circ} \mathrm{C}$ ); na segunda data (primavera) as condições climáticas foram mais favoráveis ao microrganismo, uma vez que estava um dia quente, no qual a temperatura assemelhava-se com aquela a qual é a ideal ao crescimento bacteriano (aproximadamente $30^{\circ} \mathrm{C}$ ).

Outros fatores que podem ter contribuído para esta variação é a limpeza inadequada do local e, devido ao clima estar mais quente, há a hipótese de mais pessoas terem frequentando estes parques e utilizado estes bebedouros uma vez que são pontos públicos e turísticos importantes da cidade de Curitiba.

\subsubsection{Contagem de bolores e leveduras}

Os resultados obtidos na contagem de bolores e leveduras estão expressos na tabela 2. Não há preconizado um valor de referência para este parâmetro, porém pode ser um causador de doenças infecciosas em casos de presença excessiva do microrganismo, principalmente em ambientes à temperatura ambiente e com alto teor de umidade. A presença nos bebedouros dos parques analisados é inevitável devido ao manuseio do local por muitas pessoas e por estarem naturalmente em qualquer ambiente.

O aumento da quantidade de colônias da primeira coleta para a segunda realizada pode ter sido causado pelo aumento da temperatura, sendo a segunda amostra mais propícia para crescimento de fungos devido a proximidade a temperatura ideal para fungos $\left(28^{\circ} \mathrm{C}\right)$ e ainda pelo local ter alto teor de umidade, o que favorece o desenvolvimento destes microrganismos (GOMES et al., 2005).

TABELA 2 - Resultados de fungos na superfície de bebedouros de dois parques de Curitiba Paraná, expressos em UFC/mL

\begin{tabular}{c|c}
\hline Amostras & Resultados (UFC/100 $\left.\mathbf{c m}^{2}\right)$ \\
\hline A1 & 2,2 \\
A2 & 7,2 \\
B1 & 8,8 \\
B2 & 63,8 \\
\hline
\end{tabular}

*Os valores obtidos foram determinados a partir da duplicada 


\section{CONCLUSÃO}

Considerando os resultados obtidos, concluímos que as águas fornecidas nos bebedouros dos parques avaliados encontram-se em condições sanitárias e higiênicas adequadas para consumo, sem trazer riscos à saúde humana.

Porém, tratando-se das condições da superfície do bebedouro, apesar de possuir uma condição sanitária adequada, não podemos afirmar a correta condição higiênica, devido aos valores encontrados no segundo dia de coleta. A temperatura, o maior fluxo de pessoas e a higiene inadequada do bebedouro podem ser fatores que contribuíram para este resultado negativo, podendo talvez ser corrigido com uma correta e mais frequente higienização do local, independente da quantidade de pessoas circulantes e condições climáticas.

\section{REFERÊNCIAS}

AMERICAN WATER WORKS ASSOCIATION. Standard methods for examination of water and wastewater. 18th. Washington : American Public Health Association. 2005.

BERTAGNOLLI, S. M. M.; MEDEIROS, J. T.; TAVARES, G. M. D. ; LIMBERGER, J. B.; TRAESEL, A. C. Estudo de coliformes totais de fontes alternativas de água da zona rural da região centro do estado do Rio Grande do Sul. Saúde , 29 (1) : 97-102, 2003.

BOMFIM, M. V. J.; SOEIRO, G. de O.; MADEIRA, M.; BARROS, H. D. Avaliação físicoquímica e microbiológica da água de abastecimento do laboratório de bromatologia da UERJ. Revista Higiene Alimentar, São Paulo, v. 21, n. 152, p. 99103, 2007.

BRASIL, Agência Nacional de Vigilância Sanitária. Portaria n. 2914 de 12 de dezembro de 2011. Dispõe sobre os procedimentos de controle e de vigilância da qualidade da água para consumo humano e seu padrão de potabilidade.

CARVALHO, H. F.; RECCO-PIMENTEL, S. M. Moléculas importantes para a compreensão da célula e do seu funcionamento. In: A célula. 2. ed. São Paulo: Manole, 2007. cap. 2, p. 7-28.

COELHO, D. A.; SILVA, P. M. de F.; VEIGA, S. M. O. M.; FIORINI, J. E. Avaliação da qualidade microbiológica de águas minerais comercializadas em supermercados da cidade de Alfenas, MG. Revista Higiene Alimentar, São Paulo, v. 21, n. 151, p. 88-92, 2007. 
FERNANDEZ, A. T.; SANTOS, V. C. dos. Avaliação de parâmetros físico-químicos e microbiológicos da água de abastecimento escolar, no município de Silva Jardim, RJ. Revista Higiene Alimentar, São Paulo, v. 21, n. 154, p. 93-98, 2007.

GOMES, P. C. F. de L.; CAMPOS, J. J.; MENEZES, M. de; VEIGA, S. M. O. M. Análise físico-química e microbiológica da água de bebedouros de uma IFES do sul de Minas Gerais. Revista Higiene Alimentar, v19, n. 133, p. 63-65, 2005.

LIBÂNIO, P. A. C.; CHERNICHARRO, C. A. L.; NASCIMENTO, N. O. A dimensão da qualidade de água: avaliação da relação entre indicadores sociais, de disponibilidade hídrica, de saneamento e de saúde pública. Engenharia Sanitária e Ambiental,10 (3): 219-228, 2055

NASCIMENTO, N. O.; HELLER, L. Ciência, tecnologia e inovação na interface entre as áreas de recursos hídricos e saneamento. Revista Engenharia Sanitária Ambiental, Vol.10 (1), p. 36-48, 2005.

NEWPROV. Guia de Procedimento para utilização do kitACQUAPLUS II. 2010

PINTO, A.J.T.; KANEKO M.T.; OHARA T.M. Controle Biológico de Qualidade de Produtos Farmacêuticos, Correlatos e Cosméticos. 2ed. São Paulo: Atheneu, 2003.

SILVA, N. da; JUNQUEIRA, V.; SILVEIRA, N. F. A.; TANIWAKI, M. H.; SANTOS, R. F. S. dos, GOMES, R. A. R. Manual de métodos de análise microbiológica de alimentos e água. 4 edição. São Paulo: Livraria Varela, 614p, 2010.

SILVA, R. C. A.; ARAÚJO, T. M. Qualidade da água do manancial subterrâneo em áreas urbanas de Feira de Santana (BA). Ciência \& Saúde Coletiva, 8 (4): 1019-1028, 2003

SPERLING, M. V. Noções de qualidade das águas. In: Introdução à qualidade das águas e ao tratamento de esgotos. 2. ed. Belo Horizonte: Departamento de Engenharia Sanitária e Ambiental - UFMG, v. 1. cap. 1, p. 11-50, 1996

TORTORA, G. J.; FUNKE, B. R.; CASE, C. L. Microbiologia. $8^{a}$ Edição, Editora Artmed, 2005.

UNITED STATES PHARMACOPEIA (USP). 24th ed. Rockville: Twinbrook Parkway, 2000 
WHO (World Health Organization). Guidelines for Drinking-Water Quality. Geneva: WHO, 2008 